\title{
Correction to: Interleukin-23 instructs protective multifunctional CD4 T cell responses after immunization with the Mycobacterium tuberculosis subunit vaccine H1 DDA/TDB independently of interleukin-17A
}

Kristina Ritter ${ }^{1}$ Jochen Behrends ${ }^{2} \cdot$ Hanna Erdmann ${ }^{1} \cdot$ Jasmin Rousseau ${ }^{1}$ - Alexandra Hölscher · Johanna Volz . Immo Prinz ${ }^{3,4}$. Thomas Lindenstrøm ${ }^{5}$. Christoph Hölscher ${ }^{1}$ (D)

Published online: 27 September 2021

๑) Springer-Verlag GmbH Germany, part of Springer Nature 2021

\section{Correction to: Journal of Molecular Medicine https://doi.org/10.1007/s00109-021-02100-3}

The citations and references do not match in the previously published paper.

The original article has been corrected.

Publisher's Note Springer Nature remains neutral with regard to jurisdictional claims in published maps and institutional affiliations.

The original article can be found online at https://doi.org/10.1007/ s00109-021-02100-3.

Christoph Hölscher

choelscher@fz-borstel.de

1 Infection Immunology, Research Center Borstel, Borstel, Germany

2 Research Center Borstel, Fluorescence Cytometry Core Unit, Borstel, Germany

3 Institute of Immunology, Hannover Medical School, Hannover, Germany

4 Center for Molecular Neurobiology Hamburg, Eppendorf University Medical Center, Hamburg, Germany

5 Department of Infectious Disease Immunology, Statens Serum Institut, Denmark15706 A Coruña, Copenhagen, Spain 